\title{
RUMOS DEMOCRÁTICOS BRASILEIROS FORA DO IDEALISMO
}

\section{DEMOCRATIC BRAZILIAN WAYS OFF IDEALISM}

\begin{abstract}
EMERSON ADEMIR BORGES DE OLIVEIRA
Mestre e Doutor em Direito do Estado pela Universidade de São Paulo (USP). Pós-Doutorando em Direito pela Universidade de Coimbra. Professor Assistente Doutor na Universidade de Marília. Sócio e Advogado da Borges \& Muller Advocacia.

$\underline{\text { borgesdeoliveira@usp.br }}$
\end{abstract}

\section{RESUMO}

O problema suscitado pelo presente trabalho é a impossibilidade do desenvolvimento da democracia que torne o modelo perfeito, sempre o apresentando cambiante e falho. Partindo da concepção de Rousseau de que a democracia estaria plasmada num governo dos deuses, e percebendo-se a impossibilidade de sua concretização em tal plano, a identificação de um modelo de democracia que apresenta graves falhas e ranhuras é imprescindível para saber até que ponto se busca atingir um modelo democrático, ou se a busca, na verdade, representa uma ilusão vivenciada em pleno seio da democracia. Na verdade, a crise institucional brasileira se deve em grande parte às frustrações decorrentes de se perquirir um modelo inalcançável e desafinado com a realidade democrática nacional. $E$ é justamente na fuga de uma democracia idolatra que se mostra pleno o caminho para superação dos fundamentos das insatisfações populares, realçando-se com mais profundidade os aspectos peculiares da democracia em processo brasileira. A própria crise de representatividade é um dos aspectos, como se verá, em que a perspectiva ideal apenas serve para agredir ainda mais a já combalida instituição da representação popular. Sem uma democracia possível, o país lutará eternamente para tentar remediar um ciclo infinito de crise, atacando suas consequências, jamais as causas.

Palavras-chave: Democracia. Idealismo. Reconstrução.

\begin{abstract}
The main question raised by this study in the impossibility of democracy development under a perfect model, conceiving this changing and flawed. From the conception of Rousseau, which the democracy would be shaped in a government of gods, and realizing the impossibility of its realization in such plain, the identification of a model of democracy that has serious flaws and grooves is essential to know to what extent it seeks to achieve a democratic model, our if the ssek, as a matter of fact, represents an illusion experienced in deep core of democracy. Actually, the institutional brazillian crises is being caused by the frustrations arising from assert an unattainable and discord model with the national democratic reality. And it's precisely in the escape from an idolater democracy that the full path to overcoming the fundamentals of popular dissatisfaction shows itself, deeply highlightining the peculiar aspects of the processing brazillian democracy. The crisis of representation, itself, is one of the aspects, as we will see, wherein the optimal approach only serves to further harm the already battered institution of popular representation. Without a possible democracy, the country will fight forever to try to remedy an endless cycle of crisis, attacking its consequencies, never the reasons.
\end{abstract}

Keywords: Democracy. Idealism. Reconstruction.

\section{SUMÁRIO}

INTRODUÇÃO; 1 A INVERSÃO DA LÓGICA IDOLATRA; 2 RUMOS DEMOCRÁTICOS FORA DO IDELISMO; CONCLUSÃO; REFERÊNCIAS. 


\section{INTRODUÇÃO}

$\mathrm{Na}$ constante perquirição da viabilidade dos regimes democráticos, muitas construções científicas, ao longo da história do Estado, desenharam-se, abarcando desde o conceito em si até as mais variadas temáticas insertas no tema democracia. Melhor dizendo, desde os fundamentos democráticos até os instrumentos que the servem, com profundas discussões acerca de quais seriam esses instrumentos e quais os elementos que perfazem a democracia.

O direito constitucional, ao engendrar a estruturação do Estado Democrático de Direito, conduziu a democracia para o cerne do Estado, reconhecendo o exercício democrático da política como substancial para o desenvolvimento estatal. Mais do que isso: ao abarcar, em seu núcleo, outros elementos, garantiu que, além da democracia, muitos instrumentos recebessem a especial proteção do Estado, principalmente as essenciais igualdade e liberdade.

0 problema maior, no entanto, com que se tratou a democracia até então, diz respeito à sua especial condição cambiante e a possibilidade de, em razão da variação dos seus elementos - e da variação da própria gama de elementos -, identificar tanto um modelo de democracia, que assim pudesse ser alcunhado, um conceito para o regime democrático e a forma com que devem eles se relacionar com a democracia em si.

Logo, a dissensão formou-se não apenas em relação ao conceito da própria democracia, mas quanto aos elementos que the perfazem e ao alcance dos mesmos. Nem poderia ser diferente, quando se trabalha com elementos tão polissêmicos e repletos de sentido e historicidade como liberdade e igualdade, os principais. Mesmo o povo, que permite diferenciações objetivas, será objeto de eternas discussões, ante a subjetividade do critério de objetivação.

Nesse sentido, a democracia erigiu-se como uma expressão extremamente relativizada, admitindo-se regimes tão distintos no interior do seu conceito, a partir da combinação dos elementos satelitários.

A partir de então, visualizando os problemas que enfrentavam os regimes democráticos, ergueram-se teorias, com forte reforço rosseauniano, acerca dos quais a democracia, em si, estaria calcada num plano ideal, servindo como espelho para as democracias práticas. Assim, em abstrato, a democracia, ainda que irrealizável, funcionaria como objetivo para os regimes democráticos. 
Ocorre que, diante das dificuldades e das variáveis que apontamos, não é possível, sequer em abstrato ou teoricamente, desenhar os contornos de uma suposta democracia ideal, a servir de base para os regimes reais. Toda análise democrática é permeada pela subjetividade, pela historicidade e pelo contexto geopolítico. E, inexistindo no plano ideal, não pode servir de base a qualquer desenvolvimento democrático.

O objetivo - e o foco - deste trabalho é inverter esse pressuposto que elenca a democracia a um nível de idealização, ainda que assuma irrealizável. A ideia é simplesmente romper com tal perspectiva, para admitir que, a despeito dos modelos e conceitos sobre a democracia, esta somente se desenha na prática, a partir da análise de alguns elementos sobre os quais exista um certo consenso - de existência, mas não de nível qualitativo.

Não restam dúvidas de que é justamente a distância entre um suposto modelo de democracia e aquela vivida pelos brasileiros a principal razão para a atual crise de representatividade e para a grave resposta popular.

Contemporaneamente, compreender a democracia plasmada no seio nacional e apontar mudanças plenamente realizáveis tornou-se necessário até mesmo para garantir a segurança das nossas instituições. Cumpre lembrar que a falta de democracia palpável nas instituições é, sem dúvida, um dos fatores para a ascensão de modelos totalitários.

Assim, o deslocamento da democracia para um nível falho, com a aceitação de suas diferenciações, a ausência de um conceito universal e sua suscetibilidade às intempéries traz a necessidade do esforço deste trabalho para buscar a identificação de um modelo mais realista de democracia.

Essa leitura inverte os pressupostos até então utilizados pela doutrina para romper com uma ideia de democracia no plano ideal e os demais modelos, buscando alcançar esse plano na melhor medida possível. Novamente, o que só existe no plano ideal sequer pode ser conhecido enquanto tal. Ter-se-á na realidade mera projeção afinada com as expectativas de cada modelo real.

Assim, pode-se resumir o problema a ser enfrentado enquanto uma revisitação à concepção democrática, não mais visualizada no plano perfeito de Rousseau, para quem esta seria típica de um governo dos deuses, mas enquanto um modelo absolutamente cambiante e falho, martelado por Nietzsche. Esta alteração acerca do ponto de vista democrático tem o condão de conceder-nos uma nova plataforma acerca da satisfação democrática, de modo que esta não mais precisa se ancorar na inalcançável perfeição para poder ser classificada como democracia. Da mesma forma, seus elementos e a realização de seus institutos passam a ser 
vistos não sob a necessidade de serem perfeitamente plasmados, mas sim adequados ao contexto histórico. Isso afasta, sobretudo, uma insatisfação quanto aos institutos democráticos por não estarem estes dentro das raias que se considera ideais e passa a admitir que, na realidade, toda democracia está fora do plano ideal. Assim, a insatisfação quanto aos institutos democráticos aplicados deixaria de conduzir à insatisfação quanto à própria democracia, reverberando a necessidade de constante evolução, mas de eterna imperfeição.

Metodologicamente, o trabalho baseia-se na análise contextual e doutrinária dos modelos democráticos, desde Rousseau até os dias hodiernos, de modo a compreender eventuais críticas atuais com base no modelo de crítica ao idealismo perpetrado por Nietzsche.

$\mathrm{Na}$ tarefa de jardineiros, e não de mecânicos, das questões democráticas, é salutar se valer das recomendações de prudência de Aron para as relações internacionais, agindo-se em função da singularidade dos casos concretos e dos dados disponíveis, "não por espírito de sistema ou por obediência passiva a uma norma ou pseudonorma”. Mais valerão, em nosso intento, objetivos concretos e acessíveis "e não objetivos ilimitados, possivelmente sem significação, tais como 'um mundo seguro para a democracia' ou 'um mundo onde não haja política de poder'"’1.

\section{A INVERSÃO DA LÓGICA IDOLATRA}

A proposta esposada ao longo deste trabalho é, como aquela que Aron fizera às relações internacionais, a de opor prudência à ilusão idealista, “seja ela jurídica ou ideológica”, e não simplesmente ao idealismo ${ }^{2}$. Opor-se ao idealismo, bem sabemos, já o faz a esmagadora maioria da ciência política. Opor-se a uma ilusão idealista, no entanto, ainda constitui desafio na compreensão democrática.

A ciência política, em geral, pode fornecer modelos - e o faz - em relação aos quais a democracia poderia se acalentar, mas não pode garantir que tais modelos possam ser transportados para outras circunstâncias geográficas e temporais. Mesmo quando Arend Lijphart oferece seus trinta e seis modelos democráticos, toma por base sua aplicação prática ${ }^{3}$.

\footnotetext{
${ }^{1}$ ARON, Raymond. Paz e guerra entre as nações. Brasília: UnB, Instituto de Pesquisa de Relações Internacionais; São Paulo: Imprensa Oficial do Estado de São Paulo, 2002.

${ }^{2}$ Ibidem. p.710.

${ }^{3}$ LIJPHART, Arend. Patterns of democracy: government forms and performance in thirty-six countries. New Haven: Yale University Press, 1999.
} 


\section{政

Não se negue que o objetivo de todo projeto democrático deva ser a busca por uma ou outra orientação de governo. No entanto, partindo de Spinoza, Manoel Gonçalves lembra que no político domina mais o sentimentalismo do que a razão. Orientação de governo é, no mais das vezes, uma infundada tentativa de racionalizar o discurso eleitoral, mormente criada pela mídia, para subtrair a verdadeira essência da disputa política ${ }^{4}$.

Eis a razão pela qual a esmagadora maioria dos partidos que alcançam o poder preferem vertentes ideológicas mais centrais, sem o enfrentamento decisivo de temas complexos ou polêmicos. Preferem a opção "sobre o muro", típica daqueles que manuseiam a manutenção do controle do poder. Apenas.

Veja-se, a este propósito, o desvio que a política tem proporcionado ao Judiciário na inação do Legislativo, como, por exemplo, o julgamento da Arguição de Descumprimento de Preceito Fundamental 54, acerca do aborto de anencéfalos, temática em que os criadores da lei se mostraram sempre recalcitrantes. Até mesmo o Executivo prefere posições mais tradicionalistas sobre o tema, sobretudo de influência religiosa.

Não que tal inação seja a única razão da politização do Judiciário, mas não se deve ignorar que a falta de coragem para o enfrentamento de questões sensíveis é também uma das razões que as desvia para o Judiciário.

Mas, ao contrário do que se possa pretender afirmar, este não é um desvio do poder político democrático. Ao contrário, a ele é inerente. É inerente que num flanco aberto de oposição, com "bilhetes de retorno", e sem garantia alguma de perpetuação no poder, o político tente ao máximo se valer da mais-valia de decidir, em caráter animoso, apenas o óbvio, se não quiser ser relegado a segundo plano no próximo pleito.

Isso quer dizer que a oposição na política acaba perfazendo um jogo de disputa proporcional ao risco. Apenas ataca com mais gravidade ou toma posições menos ortodoxas aquele que está alijado, ao menos temporariamente, da disputa do poder. Mesmo a oposição ao governo que se encontra em reais condições de alcançá-lo prefere ser mais tradicionalista.

Por outra via, se aquele que se encontra mais marginalizado obter sucesso na disputa política - não apenas em nível Executivo, mas principalmente Legislativo, que tem a característica de ser muito mais plural -, deixa de atuar de forma heterodoxa e trocará tais posicionamentos por métodos mais tradicionais, no intuito de não perder o status obtido.

\footnotetext{
${ }^{4}$ FERREIRA FILHO, Manoel Gonçalves. A democracia no limiar do século XXI. São Paulo: Saraiva, 2001. p.25. Em continuidade: "Ademais, os programas, seja dos partidos, seja dos candidatos, são sempre vagos, imprecisos, porque visam a aliciar o maior número, procurando chocar o mínimo possível”.
} 
Essa classe dirigente que efetivamente governa - como já prelecionara Gaetano Mosca em seu Elementi di scienza politica, de 1896 -, em vista do fato de que as decisões fundamentais são impossíveis de serem tomadas por todos e razoável que não seja por apenas um, pode estar ou não aberta aos ecos da maioria que os escolhe ${ }^{5}$.

$O$ problema é que a poluição eleitoral nasceu junto com a política e com a sociedade. $E$ todos os esforços têm o condão tão somente de amenizar tais impactos. A poluição existe para eleger, para manter e para dirigir. Não há eleições em que o povo não esteja sendo, minimamente, vítima de algum engodo. Assim como não há decisão que seja puramente neutra e alheia a quaisquer impactos, salvo uma construção racional.

Lembre-se, à guisa de exemplo, a razoável posição do Ministro Gilmar Mendes no julgamento dos RO 801 e no AgRgAg 5.282, pelo Supremo Tribunal Federal, no sentido de que a publicação e a prestação de informação sobre os atos municipais não tem o condão de, por si só, proporcionar propaganda ilegal. E não discordamos desse posicionamento.

Mas não se pode ignorar que, como lembrou o próprio Ministro, aquele que detém o poder e busca a reeleição tem em suas mãos a "mais-valia” política da máquina institucional. $\mathrm{E}$ isso certamente corresponde a uma espécie de poluição do processo eleitoral. Ainda mais nos tempos atuais em que a publicidade dos atos pode decorrer de formas múltiplas e de rápida disseminação.

Além disso, uma outra decorrência do regime democrático é o fato de que a classe dominante não pretende ser excluída do processo tão cedo e, para tanto, "chuta a escada", impedindo ao máximo a ascensão daqueles que almejam o poder.

É claro que não se deve olvidar, conforme Manoel Gonçalves, que existe mobilidade e trânsito entre a elite e a mass ${ }^{6}$. E, na realidade, a intensidade desse trânsito pode oferecer um excelente indicador do grau democrático de um país. Entre nós, tivemos a oportunidade de visualizar um partido de base operária ascender ao mais alto grau do Executivo nacional, embora muito se discuta sobre a manutenção dessa mesma raiz ao longo de seu desenvolvimento. $\mathrm{E}$ como acentua Renato Janine, “mesmo nós, que jogamos um jogo novo, podemos e devemos usar os tabuleiros existentes"7.

Mas é fato que, ainda sim, a classe dominante marca papel fundamental na história política do país.

\footnotetext{
${ }^{5}$ FERREIRA FILHO, Manoel Gonçalves. A democracia possível. 2.ed. São Paulo: Saraiva, 1974. p.22-23.

${ }^{6}$ Ibidem. p. 25.

${ }^{7}$ RIBEIRO, Renato Janine. A Ética na Política. São Paulo: Lazuli Editora, 2006. p.68.
} 


\section{政

Recentemente, o ex-presidente José Sarney anunciou que não mais se candidataria a cargos públicos. Sua história política, no entanto, remonta ao ano de 1955, quando assumiu suplência de deputado federal. Com 59 anos de carreira política - a mais longa do Brasil - e 36 anos de senado - superando Ruy Barbosa com 31 -, Sarney atuou sob quatro Constituições (1946, 1967, 1969 e 1988) e quinze Presidentes diferentes. Além de deputado federal, foi governador do Maranhão, Senador pelo Maranhão e Amapá e presidente da República.

Mas, para os fins que aqui interessam, deixou marcada sua hereditariedade política. 0 filho Zequinha Sarney foi eleito deputado estadual em 1978 e deputado federal por sete mandatos consecutivos. Roseana Sarney, a filha, foi deputada federal e governadora do Maranhão por quatro mandatos, chegando a ser pré-candidata à Presidência da República, pelo PFL, em 2001. Apenas o filho Fernando Sarney não veio a ocupar cargo público, embora se apresente nos bastidores da política.

Vários exemplos poderiam ser dados em terras tupiniquins acerca das chamadas “oligarquias políticas", a demonstrar que, ainda hoje, há papel preponderante da classe dirigente na sua perpetuação hereditária. Cite-se a esse propósito a corrida presidencial de 2014, em que figuraram entre os três principais candidatos Aécio Neves, neto de Tancredo Neves, que exerceu sua carreira política ao longo de cinquenta anos, e Eduardo Campos falecido pouco menos de dois meses das eleições -, neto de Miguel Arraes, três vezes governador de Pernambuco ${ }^{8}$.

Nos Estados Unidos, um dos pré-candidatos mais fortes à corrida republicana é Jeb Bush, governador da Flórida entre 1999 e 2007, filho do ex-presidente George Bush, que governou os Estados Unidos entre 1989 e 1993 e irmão de George W. Bush, presidente dos Estados Unidos entre 2001 e 2009.

A concepção da Teoria das Elites, segundo a qual o poder estaria centralizado nas mãos de um pequeno grupo que o monopoliza, não é recente e nem exclusividade brasileira. Gaetano Mosca fora que, visualizando o fenômeno, instituiu os pressupostos de identificação do mesmo

\footnotetext{
${ }^{8}$ Como assevera Gaetano Mosca, os líderes dessa minoritária classe política, em geral, se destacam por certas qualidades, como superioridade intelectual, moral, riqueza, militar etc ou são herdeiros daqueles que possuem tais qualidades. MOSCA, Gaetano. Elementi di Scienza Politica. Roma: Fratelli Bocca, 1896. p.64. Ainda: "A propósito, precisamos fazer duas observações: a primeira é que todas as classes políticas têm uma tendência a se tornar de fato, se não de direito, hereditárias". p.74. Também Michels: "Ninguém seriamente engajado no estudo histórico pode deixar de perceber que todas classes que já se tornaram dominantes se dedicam a transmitir a seus descendentes o poder político adquirido". MICHELS, Robert. Political parties: a sociological study of the oligarchical tendencies of modern democracy. Kitchener: Batoche Books, 2001. p.13.
} 
em 1896, embora encontremos na filosofia antiga algumas observações, não sistematizadas, em mesmo sentido. Após ele, muitos abarcaram a temática, como Pareto, Michels e Dahl.

Para Mosca, a sociedade, ainda que se alcunhe democrata, é, em realidade, oligárquica, em que, politicamente, identificam-se apenas duas classes: os governantes, isto é, a elite política que mantêm o poder, e os governados, ou o resto da população. Esta elite tem-se em si cernes tão profundos que, valendo-se de todos os meios políticos possíveis, sabe-se manter, com o tempo, no poder, passando-o entre gerações de pessoas dispostas em mesmo sentido?.

O maior problema, diante de tais dados, é que não se vislumbra uma substituição da classe dirigente pela massa de forma imediata. Como ressalta Manoel Gonçalves, “derrubada que seja uma elite dirigente por um movimento de massa, a desorganização e o esboroamento da estrutura social e política só serão evitados se da massa surgir uma minoria capaz de substituir a antiga autoridade, tomando o seu lugar e assumindo suas funções”" ${ }^{10}$.

Por isso, Manoel Gonçalves defende como elemento da democracia “um certo 'pessoal' (personnel) político", isto é, a existência de um corpo de pessoas "aberto à ascensão dos que sejam capazes, embora nascidos nas classes mais modestas" 11.

Para se ter uma ideia da discussão que essa vertente provoca, Robert Dahl, nos anos 60, envolveu-se em uma polêmica intelectual com Wright Mills acerca da natureza política dos Estados Unidos. Mais reacionário, Mills afirmava que os Estados Unidos eram controlados por uma elite unitária e restrita. Já Dahl afirmava que, na realidade, existiam várias elites diferentes, contrabalanceando-se em situações de conflito e de união. Esta, aliás, constitui uma identificação mais clara do processo democrático brasileiro.

Ora, dentre um dos critérios que Dahl elege como necessários para a configuração de um regime democrático, indica a participação efetiva. Define:

Ao longo de todo processo de tomada de decisões vinculativas, os cidadãos devem ter uma oportunidade adequada e igual de expressar suas preferências quanto ao resultado final. Devem ter oportunidades adequadas e iguais de colocar questões na agenda e de expressar seus motivos para endossar um resultado e não outro ${ }^{12}$.

\footnotetext{
${ }^{9}$ MOSCA, Gaetano. Elementi di Scienza Politica. Roma: Fratelli Bocca, 1896. p.60-83.

${ }^{10}$ FERREIRA FILHO, Manoel Gonçalves. A democracia possível. 2.ed. São Paulo: Saraiva, 1974. p.23.

${ }^{11}$ FERREIRA FILHO, Manoel Gonçalves. A democracia no limiar do século XXI. São Paulo: Saraiva, 2001.p. 29.

${ }^{12}$ DAHL, Robert A. A democracia e seus críticos. São Paulo: Editora WMF Martins Fontes, 2012. p. 171.
} 
$\mathrm{E}$, vinculado a esse, sugere um quarto critério: 0 demos deve ter a oportunidade exclusiva de decidir como as questões serão colocadas na agenda de assuntos a serem decididos mediante o processo democrático ${ }^{13}$.

Ocorre que, com raras exceções, o que se assiste na prática é o esgotamento da participação do cidadão no momento de escolha do candidato, havendo baixíssimo entroncamento popular no exercício do mandato. A classe dirigente, na realidade, prefere deixar o povo fora da participação desse processo. Acaba sendo uma luta, da classe mais fraca, ante a maré. Urge aí a necessidade do apelo popular pelos ainda alijados políticos para que sua ascensão permita a efetivação de promessas eleitoreiras.

Mesmo instrumentos nacionais que poderiam auxiliar tal participação ou são esquecidos ou são desvirtuados. Cite-se, por exemplo, a ausência de instalação do Conselho de Responsabilidade Fiscal, nos termos do artigo 67 da Lei Complementar 101/2000, que convoca "entidades técnicas representativas da sociedade" para o "acompanhamento e avaliação, de forma permanente, da política e da operacionalidade da gestão fiscal”, visando, entre outras medidas, maior eficiência nos gastos públicos, na arrecadação de receitas, transparência da gestão fiscal, padronização de prestação de contas, estudos e diagnósticos fiscais etc.

A grande questão é que, para nós, e na linha deste trabalho, nada disso deve ser considerado como desvirtuamento da democracia.

Partir da concepção de Dahl, como ressalta Manoel Gonçalves, de que a democracia constitui modelo ideal inatingível e que, na realidade, o que se tem são poliarquias é, também, uma maneira indireta de se afastar de qualquer populismo democrático ${ }^{14}$.

Como ressalta Dahl, um processo democrático e um governo democrático "talvez" nunca venha a existir na realidade - preferiríamos excluir a expressão "talvez". E os critérios que usa para a averiguação de um regime democrático "representam ideias de possibilidades humanas com as quais a realidade pode ser comparada" ${ }^{15}$.

\footnotetext{
13 Ibidem. p. 179.

${ }^{14}$ FERREIRA FILHO, Manoel Gonçalves. A democracia no limiar do século XXI. São Paulo: Saraiva, 2001. p. 25.

${ }^{15}$ DAHL, Robert A. A democracia e seus críticos. São Paulo: Editora WMF Martins Fontes, 2012. p.171.
} 
0 eterno professor de Yale, falecido em 2014, reconhece que, apesar da sua teoria do processo democrático e dos elementos que aponta, na prática ela é "radicalmente incompleta" e inexiste "uma solução definitiva para a maioria" dos problemas que envolvem a democracia".

Nessa toada, Dahl aponta nove problemas teóricos que merecem profunda reflexão:

a) 0 conceito de povo para a democracia, isto é, o demos, jamais incluirá todos aqueles sujeitos às leis. Mesmo em países de sufrágio universal, há limites traçados para a participação popular. Logo, nenhum juízo geral é de fato possível ${ }^{17}$.

b) Não há uma regra decisória segura para as decisões em âmbito democrático. Mesmo o universalmente válido príncipio da maioria, esbarra em um problema de definição sobre o que seria maioria ${ }^{18}$.

c) Há nítidos problemas procedimentais para o alcance do bem público. Para alguns, todavia, deve-se priorizar os “resultados substantivos das decisões", isto é, o aspecto material, em detrimento do procedimental ${ }^{19}$.

d) 0 termo povo volta à questão no tocante à sua própria definição, mostrando-se como um dos problemas mais insolúveis da democracia. Como definir o que seria um "grupo adequado de pessoas" capaz de governar a si mesmo ${ }^{20}$

e) As ideias democráticas, de maneira geral, acabaram englobadas por tipos radicalmente diversos de sistema político: a cidade-Estado e o Estado nacional. "Será possível, portanto, especificar um conjunto único de instituições necessárias para o processo democrático" ${ }^{21}$, isto é, que possa ser aplicado indistintivamente a qualquer Estado?

f) Em face da impossibilidade do alcance de um nível ideal de democracia, qual seria um critério seguro para afirmar, na realidade, que seus requisitos são cumpridos de forma

\footnotetext{
${ }^{16}$ Ibidem. p.182. Já quase no final de sua vida, esse tom pessimista ficou mais patente no escrito How democratic is the American Constitution?, em que criticou veementemente os instrumentos democráticos norte-americanos.

${ }^{17}$ Ibidem. p.183. "Michels, com sua famosa 'lei de ferro da oligarquia' - baseada numa investigação sobre os partidos social-democratas alemães, que se dedicavam de maneira ostensiva aos princípios da democracia em suas próprias fileiras -, parecia mostrar que era necessário fazer uma escolha entre organização (aparentemente indispensável no século XX) e democracia, mas não ambas. Assim, embora a democracia, enquanto governo do povo por meio do máximo de participação de todo o povo, ainda possa ser um ideal, sérias dúvidas, postas em evidência em nome da ciência social, parecem ter se levantado quanto à possibilidade de se colocar esse ideal em prática". PATEMAN, Carole. Participação e teoria democrática. Rio de Janeiro: Paz e Terra, 1992. p. 10-11.

${ }_{18}^{18}$ DAHL, Robert A. A democracia e seus críticos. São Paulo: Editora WMF Martins Fontes, 2012. p.183-184.

${ }^{19}$ Ibidem. p.184.

${ }^{20}$ Ibidem. p.184-185.

${ }^{21}$ Ibidem. p.185.
} 


\section{(a)

satisfatória ou não? Qual a linha de separação entre o que pode e o que não pode ser considerado democrático? ${ }^{22}$

g) Uma vez edificada uma determinada poliarquia, haveria a possibilidade da mesma caminhar em direção ao ideal democrático? Para alguns utópicos, sim. Para a contracorrente do pensamento moderno, "tendências poderosas, como uma tendência universal à oligarquia, impõem limites insuperáveis às possibilidades da democratização mais ampla"23.

h) 0 desenvolvimento democrático nos Estados nacionais acabou gerando certa competição por ideias e ideais entre indivíduos e grupos capazes de influenciar o poder. Onde fica, nesse entrave, o ideal do bem comum tão arraigado à democracia? ${ }^{24}$

i) Por fim, quais são os limites e possibilidades do processo de democratização em face de um mundo cada vez mais dinâmico e globalizado? Os governos ainda não democráticos possuem condições de assim se manterem? E como poderiam ser classificados se ainda supostamente não atingiram um limiar mínimo de poliarquia? ${ }^{25}$

A partir destes questionamentos oferecidos por Robert Dahl, a primeira conclusão, pertinente ao objetivo deste trabalho, é a inutilidade/impossibilidade de um regime democrático alcunhado de ideal. É impossível por conta da falta de parâmetros tanto para definir o que seja ideal, como para definir se as demais poliarquias estariam mais próximas ou mais afastadas do mesmo. É inútil porque a democracia que se almeja é aquela real, de acordo com as condições proporcionadas pela população de um determinado Estado e em um determinado tempo, analisando-se várias variantes comumente aceitas, como grau de oposição, participação política, nível de igualdade material, liberdade etc, todas estas, igualmente, impossiveis de maior precisão.

0 regime democrático como ideal pode fazer com o que o homem mantenha sempre a cabeça nas nuvens enquanto os pés estão no chão, visualizando um horizonte que não existe enquanto a realidade passa ao largo. Seria absolutamente inútil, nos dias atuais, pretender que os governantes brasileiros decidam com base tão somente em um chamado bem comum, se é que isso existe. Toda análise irreal, que busque justificar a democracia por conceitos ideais, acabará escondendo os grandes problemas que se instauram na prática.

\footnotetext{
22 DAHL, Robert A. A democracia e seus críticos. São Paulo: Editora WMF Martins Fontes, 2012. p.185-186.

${ }^{23}$ Ibidem. p. 186.

${ }^{24}$ Ibidem. p.186.

${ }^{25}$ Ibidem. p.186-187.
} 


\section{政

\section{RUMOS DEMOCRÁTICOS FORA DO IDEALISMO}

Diante desse quadro, que se assemelha, digamos, negativista, eis que realista, surge a questão: como proceder em relação a um processo democrático naturalmente tão falho? É possível deixar de se guiar por um ideal e assumir uma imperfeição como um modelo, digamos, “ideal"? A resposta para esta pergunta é, nos termos deste trabalho, sim.

Dissemos das dificuldades ensaiadas pelas classes dirigentes para conceder acesso àqueles que se encontram fora do ambiente eleitoral. É natural, ainda, que outros obstáculos acabem se erguendo em face das classes excluídas, como, talvez o maior deles, o aspecto financeiro.

De acordo com dados do Tribunal Superior Eleitoral, a campanha eleitoral de 2014 apresentou custo total de $\mathrm{R} \$ 5,1$ bilhões, englobando as despesas dos candidatos a deputado, senador, governador e presidente, sendo a maior registrada em todos os tempos. Em 2002, os gastos declarados junto à Justiça Eleitoral foram de R\$ 792 milhões. Líderes do ranking, PT e PSDB, registraram, sozinhos, gastos de $\mathrm{R} \$ 1,121$ bilhão e $\mathrm{R} \$ 1,038$ bilhão, respectivamente. Além disso, todos os 28 partidos que elegeram deputados federais tiveram despesas declaradas superiores a R\$ 10 milhões.

Conforme análise da Revista Época, no tocante às eleições de 2010, em Roraima cada voto para deputado federal custou R\$66,16. Dentre os candidatos eleitos, Sandro Mabel (PR-GO) apresentou receitas de R\$ 4,9 milhões, menos do que Wilson Picler (PDT-PR), que ficou de fora, embora tenha arrecadado R\$ 5,6 milhões. O custo por voto mais alto foi de Edio Lopes (PMDB$\mathrm{RR})$ com a relação custo/benefício de $\mathrm{R} \$ 152,14$ por eleitor ${ }^{26}$. Em média, a eleição de cada um dos 513 deputados custou R\$ 1,2 milhão.

E, diante da ausência do financiamento público de campanha, são os próprios candidatos que, grosso modo, precisam buscar a arrecadação necessária para os custos da corrida eleitoral. Fica fácil concluir que a grande parte dos cargos eletivos no Brasil, mormente os federais, pairam na mão de pessoas com elevados recursos financeiros ou alta capacidade de captação dos mesmos.

Obstáculos como esse não parecem de simples solução. Nem mesmo se poderia afirmar, rasteiramente, que seriam solucionados pelo financiamento público das campanhas. No mais das

\footnotetext{
${ }^{26}$ Disponível em: <http://revistaepoca.globo.com/Revista/Epoca/0, ,EMI257288-18049,00QUANTO+CUSTA+SER+DEPUTADO.html>. Acesso 14 ago 2014.
} 
vezes, é apenas coletivamente ou, em alguns casos, por ocasião de uma utilização estratégica do voto proporcional ${ }^{27}$, que as classes mais abastadas chegam ao poder. Mesmo em casos de apadrinhamento político, nota-se que existe profunda tendência de conversão do apadrinhado à classe já dominante do padrinho ${ }^{28}$.

Nessa razão, o aparecimento de novas figuras políticas, desvinculadas daquelas que já ocupam cargos públicos, ocorre de maneira progressivamente morosa. Mas ocorre, desmistificando a ideia de um círculo fechado e intransponível. Para que se tenha uma ideia, nas últimas quatro legislaturas - antes da atualmente eleita -, a Câmara dos Deputados apresentou uma renovação média de cerca de $40 \%$ das cadeiras, o que inclui figuras que até então eram totalmente alijadas do círculo político.

Maior surpresa, todavia, trouxeram as eleições de 2014: a Câmara dos Deputados apresentou uma taxa de renovação de 43,5\%, com 198 novos parlamentares - que nunca antes haviam exercido o cargo de Deputado Federal. Dos 401 Deputados que tentaram se reeleger, 101 não alcançaram a pretensão ${ }^{29}$. Já no Senado Federal, das 27 vagas disponibilizadas, apenas 5 Senadores foram reeleitos, tendo-se 22 novos nomes ${ }^{30}$.

Como afirma Lipset:

A luta pela cidadania teve dois aspectos: político (acesso ao poder por meio do voto) e econômico (institucionalização do direito dos sindicatos de participar das decisões concernentes às condições e remuneração dos trabalhadores). Os representantes das camadas mais baixas agora fazem parte das classes governantes. Eles são membros do clube. A controvérsia política diminuiu nas democracias estáveis mais ricas, porque a questão política básica da revolução industrial - a incorporação dos trabalhadores ao corpo político legítimo - foi resolvida. A única questão doméstica fundamental hoje é a barganha coletiva

\footnotetext{
${ }^{27}$ Nas eleições de 2002, o candidato Enéas Carneiro, do PRONA, obteve 1.573 .112 votos para a cadeira de deputado federal por São Paulo. Com uma votação recorde e a frente de um partido pequeno, acabou levando seis cadeiras, sendo que um dos eleitos para a Câmara dos Deputados obteve apenas 275 votos.

${ }^{28}$ A lição é de Victor Nunes Leal acerca do "coronelismo": "Muitos chefes municipais, mesmo quando participam da representação política estadual ou federal, costumam ser tributários de outros, que já galgaram, pelas relações de parentesco ou amizade, pelos dotes pessoais, pelos conchavos ou pelo simples acaso das circunstâncias, a posição de chefes de grupos ou correntes, no caminho da liderança estadual ou federal. Mas em todos esses graus da escala política impera, como não podia deixar de ser, o sistema de reciprocidade, e todo o edifício vai assentar na base, que é o 'coronel', fortalecido pelo entendimento que existe entre ele e a situação política dominante em seu Estado, através dos chefes intermediários". LEAL, Victor Nunes. Coronelismo, enxada e voto: o município e o sistema representativo no Brasil. 7.ed. São Paulo: Companhia das Letras, 2012. p.63.

29 Disponível em: <http://www1.folha.uol.com.br/poder/2014/10/1528106-camara-tera-em-2015-omaior-numero-de-novos-deputados-desde-1998.shtml>. Acesso em: 16 fev. 2015.

30 Disponível em: <http://www12.senado.gov.br/jornal/edicoes/2014/10/06/senado-tem-22-novosnomes-e-cinco-reeleitos-para-2015>. Acesso em: 16 fev. 2015.
} 
quanto à divisão do produto total nos moldes do estado de bem-estar social keynesiano; mas essas questões não requerem ou precipitam o extremismo em nenhum dos lados ${ }^{31}$.

Assim, a democracia tem a capacidade de se redesenhar quando necessário, conduzindo ao processo democrático mais personagens, capazes de pluralizar o debate.

Nesse diapasão, salutar o trabalho que os partidos menores promovem em relação ao necessário pluralismo político, escorando possíveis novas figuras a serem inseridas no processo democrático.

Já dissemos, noutra oportunidade, analisando julgamento do Supremo Tribunal Federal acerca das cláusulas de barreira à brasileira (ADIs 1351 e 1354), que se tornariam praticamente nulas a propaganda partidária e o acesso ao Fundo pelos partidos menores, colocando em risco seu próprio funcionamento, e que não há representavidade democrática se não for atrelada às minorias $^{32}$.

É evidente que, em termos reais, muitos partidos pequenos podem acabar servindo a legendas de aluguel, mas esse é um risco inerente ao regime democrático. Na balança da proporcionalidade, muito pior à democracia é a extinção dos mesmos, mesmo que por vontade da maioria. A lição de Carl Schmitt é sempre atual: “quem domina 51\% pode tornar ilegal, legalmente, os $49 \%$ restantes" ${ }^{33}$.

Conforme o relatório do Ministro Marco Aurélio naquela ocasião, com as cláusulas pretendidas a maioria dos partidos nacionais acabariam ficando sem recursos e funcionamento parlamentar ${ }^{34}$.

Neste caso em questão, fora o Judiciário que exercera o seu papel contramajoritário e protegeu o regime democrático de ser arranhado pela vontade de uma maioria legislativa.

O tema da cláusula de barreira oferece-se, assim, como um vetor extremamente limitativo de posições ideológicas minoritárias, o que, sem dúvida, compromete a representatividade democrática. Felizmente, em adesão à jurisprudência alemã, o Supremo

\footnotetext{
${ }^{31}$ LIPSET, Seymour Martin. Some social requisites of democracy: economic development and political legitimacy. The American Political Science Review. Cambridge, v.54, n.1, p.69-105, mar. 1959. p.100. 32 BORGES DE OLIVEIRA, Emerson Ademir. Ativismo judicial e controle de constitucionalidade. Curitiba: Juruá, 2015. p.239-240.

${ }_{33}^{33}$ SCHMITT, Carl. Legalidad y legitimidad. Madrid: Aguilar, 1971. p. 49.

34 "Ainda no tocante à razoabilidade, mostra-se imprópria a existência de partidos políticos com deputados eleitos e sem o desempenho parlamentar cabível, cumprindo ter presente que, a persistirem partidos e parlamentares a ele integrados, haverá, em termos de funcionamento parlamentar, o esvaziamento da atuação das minorias". Voto do Min. Rel. Marco Aurélio. ADI 1.351.
} 
Tribunal Federal ressaltou que, na medida da razoabilidade e da proporcionalidade, a cláusula, tal como colocada, ofenderia o sistema constitucional eleitoral e representativo brasileiro.

Não que isso impeça qualquer cláusula limitativa, sobretudo as de caráter proporcional, extremamente úteis, como demonstrou a experiência tedesca. 0 fato é que jamais podem tais cláusulas se tornarem intimidativas da própria vontade popular, afastando os anseios ideológicos dos partidos que refletem essas proposições.

Em nome da erupção de novas ideologias, manifestações minoritárias e candidatos até então excluídos do poder, é essencial que haja vida aos partidos menores, permitindo que, na realidade brasileira, se dê continuidade e aceleração ao processo de substituição de pretensas oligarquias políticas.

Em países de desenvolvimento democrático, a fundação de uma nova democracia é completamente ilusória. O que existe, em verdade, é o desenvolvimento, progressivo, de uma democracia já existente. Apenas por revolução seria possível substituir um regime autocrático por um democrático, e mesmo um democrático por um novo democrático.

A ideia de uma participação efetiva, igual e adequada de todos os cidadãos é um engodo. Não há igual oportunidade entre todos os submetidos à uma ordem jurídica de apresentar seus motivos em prol de uma ou outra orientação política. E jamais existirá, seja qual for o grau do modelo poliárquico.

O que não condiz com o regime democrático é a total desconsideração às preferências dos cidadãos, o que não significa que exista igual consideração em relação a todos eles, como pretendia Dahl ${ }^{35}$.

Mas a democracia é a arte de buscar minimizar diferenças e uma vertente objetiva pela qual faz isso é a cláusula do voto de igual valor: one man one vote. A ideia, bastante simples por sinal, é um dos maiores baluartes do regime democrático, pois permite que, pelo menos em um dado momento, todos sejam quantativamente iguais ${ }^{36}$. Claro que entra em jogo a influência no processo eleitoral, mas essa é outra questão.

Ao menos quanto ao valor do voto, todos são iguais. Repisamos, todavia, que, em lugar algum, todos estão submetidos a qualquer sufrágio que se considere de fato universal. Sempre, e no nosso caso por questões até lógicas, alguém estará excluído desse processo. Assim, por exemplo, a Constituição excluiu os menores de 16 anos, o que não significa que pessoas nessa idade não possam ser politicamente instruídas. Mas apenas o constituinte viu por bem

${ }^{35}$ DAHL, Robert A. A democracia e seus críticos. São Paulo: Editora WMF Martins Fontes, 2012. p.172.

${ }^{36}$ Ibidem. p.172-175. 
estabelecer um limite mínimo razoável e objetivo. Logo, toda exclusão deverá respeitar dois critérios: ser razoável/proporcional e objetiva, sob pena de ser, na realidade, discriminatória e, logo, antidemocrática.

Para as eleições de 2014, o Tribunal Superior Eleitoral permitiu o voto em trânsito, um pleito antigo e necessário, de forma a viabilizar maior participação popular daqueles que estiverem fora do domicílio eleitoral nos dias de eleição. A medida contribui com um sufrágio mais amplo, embora, como se sabe, não totalmente universal.

Nessa linha participativa, em terras norte-americanas, Bruce Ackerman e James Fishkin, professores de Yale e Texas, respectivamente, apresentaram uma nova proposta, o Deliberation Day, inserta no pacote de reformas políticas a ser discutido. A pretensão dos autores é que, por meio de discussões realizadas em âmbitos locais acerca das campanhas nacionais, uma semana antes de sua ocorrência, possa ser promovida a opinião pública de massa, não apenas da elite, por meio do intercâmbio de ideias e opiniões ${ }^{37}$. Uma proposta como essa tende a incrementar qualitativamente o conceito de povo, não por alargá-lo, uma vez que inclui apenas os eleitores registrados, mas por possibilitar que o povo esteja mais afinado com o aspecto participativo que anseia $^{38}$.

Como relembram Almond e Verba, a despeito das dificuldades de se visualizar o futuro do movimento político, há muito é certo, em quase todo o mundo, que um forte aspecto da nova cultura política seria a participação. Ao longo das nações jovens do mundo “é amplamente difundida a crença de que o indivíduo atual é politicamente importante; que deve ser um

\footnotetext{
37 "O Dia da Deliberação pretende nos libertar de um forçado compromisso com valores democráticos fundamentais. Se nós podemos ter tanto a deliberação quanto a participação da massa, nós podemos infundir no processo político, periodicamente, algo que se chama consenso coletivo informado. Esse consenso envolve a participação em massa da população e seu processo de desenvolvimento é orientado por meio da reflexão que advém da informação, do pensamento, do diálogo e da análise dos temas". ACKERMAN, Bruce; FISHKIN, James S. Deliberation Day. The Journal of Political Philosophy. Malden, v.10, n.2, p.129-152, 2002. p.151-152.

${ }^{38}$ Fishkin explana: "Nós propomos um feriado nacional em que os eleitores seriam convidados para participar de grupos randômicos de discussão como uma preparação para votar na semana seguinte. Candidatos dos maiores partidos realizariam apresentações transmitidas pela mídia nacional e os pequenos grupos locais identificariam as questões principais que seriam direcionadas aos representantes locais dos partidos em relativamente pequenas reuniões realizadas simultaneamente por todo país. Incentivos financeiros seriam dados para os cidadãos participarem. 0 custo, embora alto, tornaria a democracia mais significativa e auxiliaria a inserção de um grande público, envolvendo uma grande massa de cidadãos, que estariam bem informados sobre os argumentos concorrentes". FISHKIN, James S. Consulting the people thoughtfully. In: BRENNAN, Geoffrey. Preconditions of democracy. Finland: Tampere University Press, 2006. p..9-10.
} 
membro ativo do sistema político. Grandes grupos de pessoas que até então estavam apartadas da política solicitam seu ingresso na mesma"39.

$\mathrm{Na}$ União Europeia, por exemplo, o Tratado de regulamentação traz no artigo $11^{\circ} \mathrm{a}$ previsão de que as instituições da UE deverão conferir aos cidadãos e às associações representativas a possibilidade de uma participação direta junto à Comissão Europeia acerca das ações da União. Como ensina Rudolf Hrbek, “instrumentos democráticos diretos são suscetíveis de aumentar a legitimidade das decisões”. A participação direta “é uma solução adequada para a política e apatia dos cidadãos e promove a identificação dos cidadãos com o seu sistema político", emergindo como uma condição sine qua non para o surgimento de um demos europeu ${ }^{40}$.

Outra ilusão muito comum no processo democrático é a perquirição de um suposto bem público ou comum. Mas o termo é em si extremamente ambíguo e impreciso. No máximo, como ressalta Dallari, o termo nos remeterá para um "conjunto de condições, incluindo a ordem jurídica e a garantia de possibilidades que consintam e favoreçam o desenvolvimento integral da personalidade humana"41.

Mais complexo ainda é distinguir aspectos procedimentais de aspectos substanciais para o alcance da finalidade pública, eis que quase sempre estas questões acabam se mesclando. Assim, por exemplo, após o forte apelo popular quanto à moralidade e a vida proba do candidato, a edição da Lei Complementar 135/2010 (Ficha Limpa), a despeito de seu forte aspecto substancial, acabou esbarrando em questões procedimentais no tocante à sua aplicação para as eleições de 2010, consoante decidiu o Supremo Tribunal Federal no julgamento do Recurso Extraordinário 633.703. Naquela ocasião, em face da regra procedimental do artigo 16

\footnotetext{
${ }^{39}$ ALMOND, Gabriel A.; VERBA, Sidney. La cultura política. In: RUBIO, Albert Batlle (Org.). Diez textos básicos de ciencia política. Barcelona: Ariel, 1992. p.172.

${ }^{40}$ HRBEK, Rudolf. Die Europäische Bürgerinitiative: Möglichkeiten und Grenzen eins neuen Elements im EUEntscheidungssystem. Integration. Berlin, v.35, jah./feb. 2012. p.35. Como ressalta Mill, a melhor forma de governo não é aquela em que o cidadão apenas tem voz junto ao exercício da soberania, mas a que ele, ocasionalmente, possa ser chamado a tomar parte real junto ao governo, exercendo alguma função pública. MILL, John Stuart. Representative government. London: Parker, Son and Bourn, 1861. p.37. Nesse sentido, a participação dos cidadãos junto à UE deve ter em conta as "expectativas de que os cidadãos pudessem tomar parte em um processo de tomada de decisão política, ou, pelo menos, que os decisores se sentissem normativamente vinculados pela entrada dos cidadãos". FISCHER-HOTZEL, Andrea. Democratic participation? The involvement of citizens in policy-making at the European Comission. Journal of contemporany European research. London, v.6, i.3, p.335-352, 2010. p.348.

${ }^{41}$ DALLARI DALLARI, Dalmo de Abreu. Elementos de Teoria Geral do Estado. 32.ed. São Paulo: Saraiva, 2013.p.35.
} 
da Constituição Federal, o Ministro Luiz Fux ponderou que "por melhor que seja o direito, ele não pode se sobrepor à Constituição".

Mas, quiçá, o maior problema a envolver a democracia seja justamente definir, em determinados liames, a sua existência ou não.

Como não é possível fazê-lo objetivamente, a única saída realista é a presença de indicadores democráticos, como, brilhantemente, elucida Robert Dahl em sua tabela acerca das poliarquias.

O próprio professor de Yale retoma a ideia e apresenta, resumidamente, alguns desses indicadores:

1. As autoridades eleitas são investidas constitucionalmente do controle das decisões governamentais quanto às políticas públicas.

2. As autoridades eleitas são escolhidas, e pacificamente afastadas de seus cargos, em eleições frequentes, justas e livres, nas quais a coerção é bastante limitada.

3. Praticamente todos os adultos têm o direito de votar nessas eleições.

4. A maioria dos adultos também tem o direito de concorrer a cargos públicos abertos a candidatos em geral.

5. Os candidatos têm o direito, protegido por lei, à liberdade de expressão, particularmente a expressão política, incluindo a crítica às autoridades, à conduta do governo, ao sistema político, econômico e social estabelecido e à ideologia dominante.

6. Eles também têm acesso a fontes alternativas de informação que não sejam monopolizadas pelo governo ou por nenhum outro grupo em particular.

7. Por fim, eles têm um direito efetivamente protegido por lei a formar associações autônomas e filiar-se a elas, inclusive associações políticas, como partidos políticos e grupos de interesse, que procuram influenciar o governo mediante a concepção eleitoral e outros meios pacíficos ${ }^{42}$.

Nota-se, na concepção acima, que os elementos se apresentam não como definitivos, mas como generalistas, no sentido de esclarecer que a ausência de um deles ou uma qualificação um pouco diversa não significa necessariamente ausência de um regime democrático.

Assim, a democracia real, fora dos níveis do ideal, não apresenta nem uma única e nem respostas simples. Não apresenta medições matemáticas, mas conjecturas que podem ser classificadas como democráticas.

Apostar em uma democracia enquanto ideal apenas pode servir de engodo ao povo, muitas vezes convencido de que a minoria do poder busca uma democracia sem perceber que ela já existe.

\footnotetext{
${ }^{42}$ DAHL, Robert A. A democracia e seus críticos. São Paulo: Editora WMF Martins Fontes, 2012. p.369.
} 
Portanto, não há melhor maneira de impedir o avanço da democracia, de preparar o caminho para a autocracia e dissuadir o povo de seu desejo de participação no governo do que depreciar a definição de democracia enquanto processo através do argumento de que a mesma é "formalista", levar o povo a acreditar que seu desejo será satisfeito se o governo agir em seu interesse e que, insataurado um governo para o povo, se terá alcançado a tão almejada democracia ${ }^{43}$.

Ao passo que crer na democracia como um “modelo" cambiante, instável e falho, mas que é "perfeito" nesse exato jeito de ser, desmistifica a democracia como um ente inatingível e passa a visualizar a democracia presente em cada local a cada tempo.

\section{CONCLUSÃO}

Quais, então, os rumos para a democracia nesse novo contexto que, alterando a compreensão intelectual, verte-se em benefícios práticos?

A constatação dos problemas e das questões que são inerentes a um regime instável, como identifica Dallari, levaram a uma crise do Estado Democrático e à percepção óbvia de que a democracia não é um ideal ${ }^{44}$.

Mas as discussões do entorno democrático, a bem da verdade, acabam absorvidas em prol de um bem maior. A análise elementar serve à compreensão da democracia como um todo, não apenas do entendimento do próprio elemento. Por isso, não é possível afirmar com segurança que uma baixa participação popular necessariamente conduz a um quadro antidemocrático. Os Estados Unidos se apresentam sob matriz democrática, e diante dos elementos democráticos não há dúvida de tal constatação. Mas seria o voto indireto democrático ${ }^{45}$ A resposta depende de uma análise conjuntural. Classificar o conjunto por

\footnotetext{
${ }^{43}$ KELSEN, Hans. A democracia. São Paulo: Martins Fontes, 1993. p. 145.

${ }^{44}$ DALLARI, Dalmo de Abreu. Elementos de Teoria Geral do Estado. 32.ed. São Paulo: Saraiva, 2013. p.302.

${ }_{45}$ Para Hamilton, não: “Foi igualmente julgada desejável que a eleição imediata ficasse a cargo dos cidadãos mais capazes de analisar as condições próprias da conjuntura e de deliberar livremente, combinando judiciosamente todas as razões e circunstâncias que devem influir em sua escolha. Um pequeno grupo de pessoas, selecionado por seus concidadãos entre a massa do povo, provavelmente disporá de meios e discernimento indispensáveis para realizar tão delicadas investigações (...) A escolha do Presidente não irá depender de grupos previamente constituídos - que poderiam ser alvo, de antemão, de tentativas para prostituirem seus votos - mas, em primeira instância, de um ato direto do povo da
} 


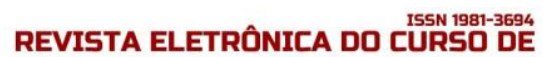

antidemocrático por conta de questões inerentes a um único elemento seria muito simplista para um problema tão complexo como a democracia.

Assim, por exemplo, há muita discussão acerca do conflito entre o valor liberdade e o voto obrigatório, entre nós. Nos termos da nossa Constituição, consoante artigo $14, \S 1^{\circ}$, I, o voto é obrigatório para os maiores de dezoito anos e, conforme inciso II, é facultativo para os analfabetos, maiores de setenta anos e maiores de dezesseis e menores de dezoito anos. E, como lembra Peña de Moraes, o alistamento também é obrigatório "no prazo de um ano da obtenção da nacionalidade brasileira"46.

Afinal, seria o sufrágio um direito ou um dever? Se visto sob o primeiro prisma, pareceria contraditório que fosse obrigatório. Analisado sob o segundo, haveria ofensa à liberdade, elemento base da democracia.

$\mathrm{Na}$ realidade, a democracia depende em grande parte de si mesma, num eterno jogo de reprodução e reconstrução. Reprodução quando os elementos parecem atender com satisfação o espírito democrático de um povo. Reconstrução, quando não.

Não se diga que foram fracassadas as tentativas democráticas nos percalços brasileiros, mormente entre os anos de 1964 e 1985. Nem que o Brasil ainda não atingiu uma democracia plena, pois isso jamais irá ocorrer, não apenas aqui, mas em qualquer lugar do mundo, ante a ausência de qualquer condição que comprove que determinado projeto democrático seja pleno.

A democracia é fruto detalhado da análise das instituições e de como seus elementos têm sido tratados nos quatro cantos do Brasil cotidianamente. O primeiro passo para uma mudança no modus operandi em relação à sua contínua efetivação é compreender a inexistência de qualquer modelo que possa nos guiar, a não ser a nossa própria vontade democrática. E, nesse contexto, o desenvolvimento de uma sociedade democrática, em que os subsistemas (família, igreja, escolas etc) se apresentem com vontade democrática, "de maneira a contribuir direta ou indiretamente para a força dos processos políticos democráticos" 47 .

América, através da eleição de pessoas com o encargo específico de realizarem a escolha, sendo excluídas do rol destas todas as que possam, por sua situação, ser tidas como muito devotadas ao Presidente em exercício. Nenhum senador, deputado ou outro cidadão exercendo cargo de confiança ou relevo nos Estados Unidos pode integrar o colégio eleitoral". HAMILTON, Alexander; MADISON, James; JAY, John. 0 Federalista. Brasília: UnB, 1984. p.517-518.

${ }^{46}$ MORAES, Guilherme Peña. Curso de direito constitucional. 5.ed. São Paulo: Saraiva, 2013. p.620. Algumas situações podem conduzir à perda ou suspensão dos direitos políticos nos termos do artigo 15, da CF. p.621-622.

${ }^{47}$ DAHL, Robert. A moderna análise democrática. Rio de Janeiro: Lidador, 1966. p.26. 
A democracia é esta que vivenciamos, que urge das ruas, das manifestações contrárias ou favoráveis à classe política, do exercício de sufrágio e que nele não se esgota. A contraprestação dos governantes em assistir o povo em suas necessidades é - ou deveria ser - a medida exata da manutenção ou perda do próprio poder. A omissão, em locais de livres debates e eleições, é, como diria Maquiavel, “o apressamento da sua ruína”48.

Como leciona Antônio Manuel Martins, a “construção de sociedades democráticas exige, entre outras coisas, a invenção corajosa e realista de modelos de democracia realizáveis"49.

O que é inaceitável é olhar para uma democracia sem corpo, afastada dos indivíduos que a constroem e reconstroem cotidianamente e alijada das questões fundamentais que envolvem as principais discussões que são conduzidas ao processo decisório e aos decision makers. Essa visão, aliás, além de extremamente limitada, torna impossível compreender a estrutura democrática de um determinado Estado em um determinado tempo.

o problema maior das pompas com que a democracia foi tratada até então é justamente o fato de que esse discurso esconde seus verdadeiros caracteres. Elevar a democracia aos céus, homenageá-la, conferir-lhe o título de governo dos deuses, tudo isso nada serve à compreensão do processo democrático na prática. No máximo, faz a elucubração de um conceito que sequer existe no campo intelectual-material.

\section{REFERÊNCIAS}

ACKERMAN, Bruce; FISHKIN, James S. Deliberation Day. The Journal of Political Philosophy. Malden, v.10, n.2, p.129-152, 2002.

ALMOND, Gabriel A.; VERBA, Sidney. La cultura política. In: RUBIO, Albert Batlle (Org.). Diez textos básicos de ciencia política. Barcelona: Ariel, 1992..

ARON, Raymond. Paz e guerra entre as nações. Brasília: UnB, Instituto de Pesquisa de Relações Internacionais; São Paulo: Imprensa Oficial do Estado de São Paulo, 2002.

BORGES DE OLIVEIRA, Emerson Ademir. Ativismo judicial e controle de constitucionalidade. Curitiba: Juruá, 2015.

. Ativismo judicial e o papel das Cortes Constitucionais nas correções de rota da crise da democracia representativa. Revista de Direito Público. Porto Alegre, n. 40, p. 25-49, 2011.

\footnotetext{
${ }^{48}$ MAQUIAVEL, Nicolau. Comentários sobre a Primeira Década de Tito Lívio. 3.ed. Brasília: UnB, 1994. p.107.

${ }^{49}$ MARTINS, António Manuel. Modelos de democracia. Revista Filosófica de Coimbra. Coimbra, n.11, p.85100, 1997. p.86.
} 
DAHL, Robert A. A democracia e seus críticos. São Paulo: Editora WMF Martins Fontes, 2012. . A moderna análise democrática. Rio de Janeiro: Lidador, 1966. . Poliarquia: participação e oposição. São Paulo: Edusp, s.d.

DALLARI, Dalmo de Abreu. Elementos de Teoria Geral do Estado. 32.ed. São Paulo: Saraiva, 2013.

FERREIRA FILHO, Manoel Gonçalves. A democracia no limiar do século XXI. São Paulo: Saraiva, 2001.

A democracia possível. 2.ed. São Paulo: Saraiva, 1974.

Aspectos do Direito Constitucional contemporâneo. 2.ed. São Paulo: Saraiva, 2009.

FISCHER-HOTZEL, Andrea. Democratic participation? The involvement of citizens in policymaking at the European Comission. Journal of contemporany European research. London, v.6, i.3, p.335-352, 2010.

FISHKIN, James S. Consulting the people - thoughtfully. In: BRENNAN, Geoffrey. Preconditions of democracy. Finland: Tampere University Press, 2006.

HAMILTON, Alexander; MADISON, James; JAY, John. O Federalista. Brasília: UnB, 1984.

HRBEK, Rudolf. Die Europäische Bürgerinitiative: Möglichkeiten und Grenzen eins neuen Elements im EU-Entscheidungssystem. Integration. Berlin, v.35, jah./feb. 2012.

KELSEN, Hans. A democracia. São Paulo: Martins Fontes, 1993.

LEAL, Victor Nunes. Coronelismo, enxada e voto: o município e o sistema representativo no Brasil. 7.ed. São Paulo: Companhia das Letras, 2012.

LIJPHART, Arend. Patterns of democracy: government forms and performance in thirty-six countries. New Haven: Yale University Press, 1999.

LIPSET, Seymour Martin. Some social requisites of democracy: economic development and political legitimacy. The American Political Science Review. Cambridge, v.54, n.1, p.69-105, mar. 1959.

MAQUIAVEL, Nicolau. Comentários sobre a Primeira Década de Tito Lívio. 3.ed. Brasília: UnB, 1994.

MARTINS, António Manuel. Modelos de democracia. Revista Filosófica de Coimbra. Coimbra, n.11, p.85-100, 1997.

MICHELS, Robert. Political parties: a sociological study of the oligarchical tendencies of modern democracy. Kitchener: Batoche Books, 2001. 
MILL, John Stuart. Representative government. London: Parker, Son and Bourn, 1861.

MOISÉS, José Álvaro. Cultura política, instituições e democracia: lições da experiência brasileira. Revista Brasileira de Ciências Sociais. São Paulo, v.23, n.66, p.11-43, fev. 2008.

Democracia e desconfiança nas instituições democráticas. In: (Org.). Democracia e confiança: por que os cidadãos desconfiam das Instituições Públicas? São Paulo: EdUSP, 2010. p.45-76.

. Lições de liberdade e de opressão: os trabalhadores e a luta pela democracia. Rio de Janeiro: Paz e Terra, 1992.

. Os significados da democracia segundo os brasileiros. Opinião Pública. Campinas, v.16, n.2, p.269-309, nov. 2010.

MORAES, Guilherme Peña. Curso de direito constitucional. 5.ed. São Paulo: Saraiva, 2013. MOSCA, Gaetano. Elementi di Scienza Politica. Roma: Fratelli Bocca, 1896.

NOHLEN, Dieter; ZOVATTO, Daniel; OROZCO, Jesús; THOMPSON, José (Comp.). Tratado de derecho electoral comparado de América Latina. 2.ed. México: FCE, Instituto Interamericano de Derechos Humanos, Universidad de Heidelberg, International IDEA, Tribunal Electoral del Poder Judicial de la Federación, Instituto Federal Electoral, 2007.

PATEMAN, Carole. Participação e teoria democrática. Rio de Janeiro: Paz e Terra, 1992.

RIBEIRO, Renato Janine. A Ética na Política. São Paulo: Lazuli Editora, 2006.

SCHMITT, Carl. Legalidad y legitimidad. Madrid: Aguilar, 1971.

SCHUMPETER, Joseph A. Capitalism, socialism and democracy. 2.ed. New York and London: Harper \& Brothers Publishers, 1947.

Recebido em: 20.10.2015 / Revisões requeridas em: 26.02.2016 / Aprovado em: 28.04.2016 